\title{
Ovarian Morphology and Egg Quality Traits of Egyptian Selected Strain for Egg Production Compared with Commercial Laying Strains
}

\section{-Author(s)}

\section{Nassar FS' \\ El-Komy EM"}

Abdou AM

Department of Animal Production, Faculty of Agriculture, Cairo University, Giza 12613, Egypt.

Animal Production Department, Agriculture and Biology Research Division, National Research Centre, El Buhouth St., 12311 Dokki, Cairo, Egypt.

\section{Mail Address}

Corresponding author e-mail address Farid S. Nassar

Department of Animal Production, Faculty of Agriculture, Cairo University, Giza 12613, Egypt

Tel: $\quad$ (002) 01094477024

Email: Fidsaber_nassar@agr.cu.edu.eg

\section{neywords}

Egg production, egg quality, ovarian morphology, selection, sexual maturity.

\section{ABSTRACT}

An experiment was conducted to evaluate the effect of selection for egg production performance of Cairo L-2 strain, as a local layer strain, after five generations of selection on productivity, ovarian morphology and some egg quality traits versus commercial Lohmann Brown-Lite (LBL) strain. The performance in the 5 th generation was evaluated in Cairo L-2 and LBL strains for live body weight at sexual maturity (BWSM), age at sexual maturity (ASM), first egg weight (FEW), ovarian morphology, ovarian follicles number, ovarian weights and diameter, oviduct weight, liver weight, and stroma weight and their percentages to live body weight at sexual maturity for Cairo L-2 and LBL strains. Egg traits at 36 weeks of age including: egg number (EN), egg weight (EW), shell thickness (ST), and shell index (SI) were also obtained. Current results indicated that Cairo L-2 strain had higher ASM compared with LBL strain. Also, Cairo L-2 strain had lower BWSM, oviduct, ovary, stroma, and liver absolute weights and relative ovary weight compared with LBL strain. Ovarian follicles number, weights and diameter, FEW, and EN until 36 weeks of age were higher in LBL than in Cairo L-2 strain. Also, SI of the LBL was higher than that of Cairo L-2 strain. Moreover, Cairo L-2 strain egg production until 36 weeks of age was about $80 \%$ of that of LBL strain with good ST and SI. In conclusion, there were positive responses in ovarian morphology, egg production, and egg quality traits of Cairo L-2 strain associated with breeding program.

\section{INTRODUCTION}

Commercial crosses of layer chickens in the last decades had been produced as results of intensive selection in pure strains. Also, different genetic selection programs that were used in poultry breeding for almost a hundred years, led to positive effects in improving production performance in poultry (Buzała et al., 2015). Selection index, in layers breeding programs, that includes more than 30 closely related traits made it possible for balanced genetic improvements in different traits even when the traits are negatively correlated (Blanco et al., 2014). Productive performance, in layer breeds, can be assessed through parameters such as ovary morphology, during sexual maturation, at first oviposition, and at the end of lay (Renema et al., 2001; Robinson et al., 2001).

In chicken, ovary follicular development is a continuous process from the activation of small cortical follicles to the ovulation of hierarchical follicles. Small white follicles are recruited into a hierarchy of large preovulatory follicles and become yellow due to yolk deposition (Johnson, 2015). Johnson also reported that the largest follicle (F1) ovulates almost on a daily basis and is replaced by a new pre-hierarchal follicle that is selected to enter the hierarchy each day. However, no new follicle is selected when an ovulation does not occur. 
Egg quality traits including egg weight (EW), shell thickness (ST), and shell index (SI) are very important traits in layer breeding programs due to their effect on profitability in the egg production industry (Blanco et al., 2014). EW has great economic importance in poultry breeding and is considered among the major breeding objectives (Savegnago et al., 2011). In addition, the genetic differences of the characteristics of eggshell formation are evident between breeds, strains, and families within the species (Anderson et al., 2004). In layer breeding programs, breaking strength provides an indicator of static shell resistance correlated with shell thickness. Thus, selection to improve shell quality is an important selection goal to reduce egg breakage (Arango et al., 2016). In addition, there are many factors that affect quail sexual maturity in including age, body weight, and body composition (Oruwari \& Brody, 1988). The objective of the present experiment was to study the effect of genetic selection, for egg production, on ovarian morphology at sexual maturity, egg production, and egg quality from sexual maturity until 36 weeks of age in commercial and selected local chickens strain.

\section{MATERIAL AND METHODS}

\section{Stocks and management}

A selection improvement program started since 2010 at the Animal Production Department, Faculty of Agriculture, Cairo University, Giza, Egypt, to develop the Cairo L-2 strain as a local layer strain. A total of 10 rosters from Rhoad Island Red grandparent strain males were crossed with 100 females from the native Egyptian breed Fayoumi chickens to produce the base generation of Cairo L-2 strain. Phenotypic selection was used to select the best layer breeders to produce the next generation based on a selection index utilizing age and body weight at sexual maturity, egg number, and egg weight.

After five generations of selection for egg production traits, a total of 600 day old female Cairo L-2 strain chicks were weighted and wing banded. Also, 600 day old female chicks from commercial Lohman BrownLite (LBL) strain were weighted and wing banded as a control group to Cairo L-2 strain. All chicks were reared, on deep litter, in an open house from one day old until 16 weeks of age. The rearing photoperiod was $23 \mathrm{~h}$ of light (L): $1 \mathrm{~h}$ of darkness (D) until $4 \mathrm{~d}$ of age, when the light period was shortened to 22L: $2 \mathrm{D}$, which was reduced to $16 \mathrm{~L}: 8 \mathrm{D}$ at the $2^{\text {nd }}$ week, and to $14 \mathrm{~L}: 10 \mathrm{D}$ at the $3^{\text {rd }}$ week. From the $4^{\text {th }}$ to the $16^{\text {th }}$ weeks the photoperiod was $12 \mathrm{~L}: 12 \mathrm{D}$. The diets used for Cairo L-2 and LBL strains and their calculated nutrient analyses are presented in Table 1 according to the management guide of LBL strain.

\section{Experimental design}

At 17 weeks of age, 50 pullets from each strain were chosen at random and transfered to an egg production house. Individual pullets were placed in individual laying cages to study the ovary morphology at sexual maturity. All remaining pullets, from both strains, were transfered to another egg production house and placed in individual laying cages to study the egg production and egg quality until 36 weeks of age. All birds were photo stimulated at 17 weeks of age with an initial increase in photoperiod to 14L: 10D and subsequent weekly light period increases of 30 min to a maximum day length of $16 \mathrm{~L}: 8 \mathrm{D}$ at 22 weeks. Feed and water were provided ad libitum throughout the study.

\section{Reproductive traits measured at sexual maturity}

The live body weight at sexual maturity (BWSM), age at sexual maturity (ASM), and first egg weight (FEW) for each hen were recorded on the day of first oviposition. Feed was then withdrawn, for that hen, overnight (8 to 12 hours) to facilitate gut clearance. Birds were slaughtered by slitting the throat, cutting the carotid arteries, jugular veins, esophagus and trachea without severing the head. The birds were

Table 1 - Diets used and their calculated nutrients

\begin{tabular}{|c|c|c|c|c|c|}
\hline Analyses & $\begin{array}{c}\text { Starter } \\
0-3 \text { week }\end{array}$ & $\begin{array}{l}\text { Grower } 1 \\
4-8 \text { week }\end{array}$ & $\begin{array}{c}\text { Grower } 2 \\
\text { 9-16 week }\end{array}$ & $\begin{array}{c}\text { Prelay } \\
16-20 \text { week }\end{array}$ & $\begin{array}{c}\text { Layer } \\
>20 \text { week }\end{array}$ \\
\hline$\%$ Crude protein & 20 & 18.5 & 14.5 & 17.5 & 18 \\
\hline $\mathrm{ME}^{1}$ (Kcal/kg) & 2900 & 2800 & 2750 & 2800 & 2850 \\
\hline \%Linoleic acid & 2.00 & 1.40 & 1.00 & 1.00 & 2.00 \\
\hline \%Methionine & 0.48 & 0.40 & 0.34 & 0.36 & 0.40 \\
\hline \%Lysine & 1.2 & 1.00 & 0.65 & 0.85 & 0.80 \\
\hline$\%$ Calcium & 1.05 & 1.00 & 0.90 & 2.00 & 3.73 \\
\hline
\end{tabular}

${ }^{1} \mathrm{ME}=$ Metabolisable Energy. 
dissected, and the liver, oviduct, ovary, and stroma (ovary with large, above $10 \mathrm{~mm}$ in diameter, yellow follicles (LYF removed) weights were recorded. The LYF were counted, sorted by size (with the largest follicle being the F1 follicle), and individually weighed. A yolk in the oviduct was considered the F1 follicle (most developed follicle) only prior to entry into the shell gland. The numbers of small yellow follicles (SYF; 5 to $10 \mathrm{~mm}$ in diameter) on the stroma were recorded.

\section{Egg production and egg quality traits}

Egg number (EN) was recorded for each laying hen per each strain from sexual maturity until 36 weeks of age. Also, EW was measured with a digital scale in grams with an accuracy of $0.01 \mathrm{~g}$. At 36 weeks of age, 1000 eggs from each strain were collected during 3 days to study SI and ST as indicators for egg quality traits for both strains. In addition, SI was determined with a caliper and according to the formula $\mathrm{SI}=$ (width /length) $\times 100$. To determine the ST in $(\mathrm{mm})$ a micrometer screw was used at the equatorial region.

\section{Statistical analysis}

Data were analyzed as a one-way analysis of variance using the SAS software, general linear model (SAS Institute, 2004). The main effect was strain. Traits analyzed were: age at sexual maturity (ASM), live body weight at sexual maturity (BWSM), first egg weight (FEW), ovarian follicles number, weights and diameter, oviduct weight, liver weight, and stroma as weights and as percentages of live body weight at sexual maturity for Cairo L-2 and LBL strains. Egg traits at 36 weeks of age including: EN, EW, ST, and SI were also analyzed. All data were reported as least square means $(\mathrm{LSM}) \pm$ standard errors $(\mathrm{SE})$. Mean values were separated, when significance existed, using Duncan's multiple range test (Duncan, 1955). Significance level was set at $5 \%$. The following model was used:

$$
Y_{i j}=\mu+S_{i}+e_{i j}
$$

Where, $Y_{i j}$ : The $j^{\text {th }}$ observation of the $i^{\text {th }}$ strain.

$\mu$ : The overall mean.

\section{$S_{i}$ : The effect of the $i^{\text {th }}$ strain. \\ $\mathrm{e}_{\mathrm{ij}}$ : Experimental error.}

\section{RESULTS AND DISCUSSION}

\section{Age and body weight at sexual maturity}

Results in table (2) indicated that, Cairo L-2 strain had higher ASM compared with LBL strain by 13 days. Intensive genetic selection of layer hens for economically important production traits results in considerable differences in the mechanisms of growth and development (Buzała et al., 2015). Sexual maturity, defined as age at production of the first egg, is influenced by chronological age, body weight, and body composition (Oruwari \& Brody, 1988). Also, LBL strain started lay 13 days earlier than Cairo L-2 when photo stimulated at the same age (Table 2). Renema et al. (2001) found that a modern layer strains started to lay 9.1 days earlier than an antique strain when photo stimulated at the same age. Thus, strain differences in response to photo stimulation are present.

Cairo L-2 strain had lower BWSM compared with LBL strain by $214 \mathrm{~g}$ (Table 2). It was reported that BWSM was strongly affected by strain (Renema \& Robinson, 2001). They stated that, there were differences in BWSM between four strains of commercial egg layers, two white egg strains, ISA-White and Shaver 20003, and two brown egg strains, ISA-Brown and Shaver 5793, associated with effects of light intensity from photo stimulation in layers. The current results indicated that, LBL strain reached sexual maturity significantly $(p \leq 0.05)$ earlier than Cairo L-2 strain. This is most probably due to a longer, more intense selection for LBL strain than Cairo L-2 strain.

\section{Reproductive morphology at sexual maturity}

Results in Tables (2 and 3) indicated that, Cairo L-2 strain had lower oviduct, ovary, stroma, and liver absolute weights and relative ovary weight compared with LBL strain. However; there were no significant

Table 2 - Least Square Means \pm SE from the ANOVA of ASM, BWSM, oviduct, ovary, stroma, and liver weights at sexual maturity in Cairo L-2 and LBL hens

\begin{tabular}{|c|c|c|c|c|c|c|}
\hline \multirow{2}{*}{ Strain } & \multirow{2}{*}{ 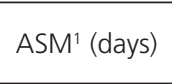 } & \multicolumn{5}{|c|}{ Weight (g) } \\
\hline & & BWSM $^{2}$ & Oviduct & Ovary & Stroma $^{3}$ & Liver \\
\hline Cairo L-2 & $158.5 \pm 1.11^{\mathrm{a}}$ & $1452.3 \pm 13.75^{b}$ & $43.1 \pm 1.27^{b}$ & $31.8 \pm 0.76^{b}$ & $2.6 \pm 0.16^{b}$ & $30.5 \pm 0.70^{b}$ \\
\hline $\mathrm{LBL}$ & $145.2 \pm 1.11^{b}$ & $1666.0 \pm 13.75^{a}$ & $51.6 \pm 1.27^{a}$ & $38.7 \pm 0.76^{a}$ & $3.6 \pm 0.16^{a}$ & $33.1 \pm 0.70^{a}$ \\
\hline
\end{tabular}

a-dMeans with different superscripts, within trait, are significantly different $(P \leq 0.05)$.

${ }^{1} \mathrm{ASM}=$ age at sexual maturity

${ }^{2} \mathrm{BWSM}=$ body weight at sexual maturity.

${ }^{3}$ Stroma=Ovary without the large yellow follicles (follicles $>10 \mathrm{~mm}$ in diameter removed). 
differences in relative oviduct, stoma, and liver weights between the two studied strains (Table 3). Oviduct weight of LBL birds were $18.5 \%$ heavier than those of Cairo L-2 birds. Ovary weight was higher in LBL birds compared with Cairo L-2 birds by $6.9 \mathrm{~g}$. Also, LBL strain had higher stroma weight $(3.56 \mathrm{~g})$ compared with Cairo L-2 birds (2.60g). Renema et al. (2001) stated that, productive performance, in layer breeds, can be assessed by using many parameters such as ovarian morphology during sexual maturation at first oviposition. Also, it is clear that layer strain primarily affected the weight of the oviduct, ovary, and ovarian follicles.
FEW, F1 weight, LYF total weight and LYF number were higher in LBL strain than Cairo L-2 strain (Table 4). However, there were no significant differences in SYF number between the two strains. On the other hand, the number of LYF were higher in LBL strain $(n=7.83)$ compared with Cairo L-2 strain $(n=6.73)$ birds. Also, the F1 follicle weight of Cairo L-2 strain (10.02g) was less than that of LBL strain (12.44g). In addition, the FEW of Cairo L-2 strain was less than that of LBL strain by $6.1 \mathrm{~g}$ (Table 4). The FEW of Cairo L-2 strain was $14.8 \%$ less than that of LBL strain.

Stifani et al. (1990) stated that the rate of yolk production appeared to be dependent on liver weight

Table 3 - Least Square Means \pm SE from the ANOVA of oviduct, ovary, stroma, and liver weights percentages relative to live body weight at sexual maturity in Cairo L-2 and LBL hens

\begin{tabular}{lllll}
\hline Strain & \%Oviduct & \%Ovary & \%Stroma & \%Liver \\
\hline Cairo L-2 & $3.0 \pm 0.09$ & $2.3 \pm 0.05^{\mathrm{b}}$ & $0.20 \pm 0.01$ & $2.1 \pm 0.07$ \\
LBL & $3.2 \pm 0.09$ & $2.4 \pm 0.05^{\mathrm{a}}$ & $0.22 \pm 0.01$ & $2.0 \pm 0.07$ \\
\hline
\end{tabular}

a-dMeans with different superscripts, within trait, are significantly different $(p \leq 0.05)$.

1 Stroma=Ovary without the large yellow follicles (follicles $>10 \mathrm{~mm}$ in diameter removed).

Table 4 - Least Square Means \pm SE from the ANOVA of FEW and ovarian follicles measurements at sexual maturity in Cairo L-2 and LBL hens

\begin{tabular}{|c|c|c|c|c|c|}
\hline \multirow{2}{*}{ Strain } & \multirow{2}{*}{$\mathrm{FEW}^{1}(\mathrm{~g})$} & \multicolumn{4}{|c|}{ Ovarian follicles } \\
\hline & & LYF total weight $^{2}(\mathrm{~g})$ & $\operatorname{LYF}^{3}(n)$ & $\mathrm{SYF}^{4}(\mathrm{n})$ & $\mathrm{F} 1^{5}$ weight $(\mathrm{g})$ \\
\hline Cairo L-2 & $35.0 \pm 0.23^{b}$ & $22.1 \pm 1.00^{b}$ & $6.7 \pm 0.13^{b}$ & $5.6 \pm 0.10$ & $10.0 \pm 0.23^{b}$ \\
\hline LBL & $41.1 \pm 0.23^{a}$ & $30.3 \pm 1.00^{a}$ & $7.8 \pm 0.13^{a}$ & $5.6 \pm 0.10$ & $12.4 \pm 0.23^{a}$ \\
\hline
\end{tabular}

a-dMeans with different superscripts, within trait, are significantly different $(p \leq 0.05)$.

${ }^{1} \mathrm{FEW}=$ first egg weight

${ }^{2} \mathrm{LYF}$ total weight $=\mathrm{LYF}$ weight without F1 follicle

${ }^{3} \mathrm{LYF}=$ large yellow follicles (>10 $\mathrm{mm}$ in diameter)

${ }^{4} \mathrm{SYF}=$ small yellow follicles (5 to $10 \mathrm{~mm}$ in diameter)

${ }^{5} \mathrm{FI}=$ heaviest large yellow follicle.

and total liver lipids. They also stated that the yolk proteins are synthesized in the liver through the action of estrogen, and these proteins are taken into the oocyte by a specific lipoprotein receptor with 8 ligand binding domains. This might explain the higher number of the LYF and their total weight and the F1 weight of LBL strain than Cairo L-2 strain. Shivaprasad \& Jaap (1977) stated that an increase of liver lipids is indicated by an increase in liver weight as the bird approaches sexual maturity and that increase in liver weight preceeds, or coincide with, the increase in liver lipids.

\section{Egg production and egg quality at 36 weeks of age}

LBL strain had higher EN compared with Cairo L-2 strain by 18 eggs until 36 weeks (Table 5). Renema et al. (2001) stated that the reduction in the number of
LYF causes reduced egg production. This explains the higher EN in LBL strain, until 36 weeks of age, over Cairo L-2 strain. The common objective of commercial laying stocks is to increase the EN produced per unit time, thus, egg productivity is the most important economic trait in egg-laying poultry (Kim et al., 2004).

In addition, LBL strain birds had higher average EW compared with Cairo L-2 birds until 36 weeks of age by $9 \mathrm{~g}$ (Table 5). The EW has great economic importance in poultry breeding and is considered among the major breeding objectives and research goals (Savegnago et al., 2011). Therefore, producing eggs of appropriate size and weight is a key issue for both producers and breeders. Cavero \& Schmutz (2009) found a negative correlation between EW and hatchability in Leghorn layers. They suggested to confine the selection for better hatchability for female strains and to select the male strains for higher egg weight in the layers 
Table 5 - Least Square Means \pm SE from the ANOVA of EN, EW, ST, and SI at 36 weeks of age in Cairo L-2 and LBL hens

\begin{tabular}{lllll}
\hline Strain & $\mathrm{EN}^{1}$ & $\mathrm{EW}^{2}(\mathrm{~g})$ & $\mathrm{ST}^{3}(\mathrm{~mm})$ & $\mathrm{Sl}^{4}(\mathrm{~mm})$ \\
\hline Cairo L-2 & $74.0 \pm 2.23^{\mathrm{b}}$ & $47.0 \pm 1.20^{\mathrm{b}}$ & $0.35 \pm 0.19$ & $76.0 \pm 0.15^{\mathrm{b}}$ \\
LBL & $92.0 \pm 2.23^{\mathrm{a}}$ & $56.0 \pm 1.20^{\mathrm{a}}$ & $0.34 \pm 0.19$ & $79.0 \pm 0.15^{\mathrm{a}}$ \\
\hline
\end{tabular}

${ }^{a-d}$ Means with different superscripts, within trait, are significantly different $(p \leq 0.05)$.

${ }^{1} \mathrm{EN}=$ egg number

${ }^{2} \mathrm{EW}=$ egg weight

${ }^{3}$ ST=shell thickness

${ }^{4} \mathrm{~S} \mid=$ shell index.

breeding programs. Thus, it is possible to obtain a good hatchability at the parent stock level and to reach a good egg weight level in the commercial hybrid layer. In the breeding of program Cairo L-2 strain, selection for higher EW was practiced in all generation. Thus, we expect an improvement in EW along with the EN.

Egg quality traits are very important in layer breeding programs. This is due to their effect on profitability in the egg production industry and on the production of quality chicks. The ST and SI are positively correlated with breaking strength (Blanco et al., 2014). Also, eggshell with lower quality than desired may lead to contamination of the important content (yolk and albumen), compromising the dietary health of consumers and determined the number of salable eggs output in the layer industry (Cordeiro et al., 2017). Results in the current study indicated that, there were no differences between Cairo L-2 and LBL birds in ST. However, there were differences in SI between Cairo L-2 and LBL birds. The SI of Cairo L-2 strain was 76 and the SI in LBL was 79 (Table 5). According to Cavero \& Schmutz (2009) SI has a negative correlation with hatchability. Thus, rounded eggs will have lower hatchability. Moreover, Genetic differences in eggshell formation characteristics are evident between breeds, strains, and families within the species (Anderson et al., 2004).

\section{CONCLUSION}

In conclusion, the common objective of commercial breeders of laying stocks is to increase the number of eggs produced per unit of time with enhancement of egg quality traits. Thus, the main objectives of layer breeding programs are complicated. Results show that Cairo L-2 strain egg production until 36 week of age, on average, about $80 \%$ of that of LBL strain after 5 generations of selection for egg production of Cairo L-2 strain. In addition, there were positive responses in ovarian morphology, egg production, and egg quality traits of Cairo L-2 strain as a result of selection program. In Cairo L-2 strain future generations, to achieve proper egg production and egg quality, our team will focus on control the dynamic changes by using genetic selection and environmental regulation. Also, if these improvements of Cairo $L-2$ strain will continue with the same rate, it might be expected that after a few generations of selection, Cairo L-2 strain might be a potential for a commercial local layer strain.

\section{REFERENCES}

Anderson KE, Tharrington JB, Curtis PA, Jones FT. Shell characteristics of eggs from historic strains of Single Comb White Leghorn chickens and the relationship of egg shape to shell strength. International Journal of Poultry Science 2004;3(1):17-19.

Arango J, Wolc A, Settar P, O'Sullivan NP. Model comparison to evaluate a shell quality bio-complex in layer hens. Poultry Science 2016;95(11):2520-2527.

Blanco AE, Icken W, Ould-Ali D, Cavero D, Schmutz M. Genetic parameters of egg quality traits on different pedigree layers with special focus on dynamic stiffness. Poultry Science 2014;93(10):2457-2463.

Buzała M, Janicki B, Czarnecki R. Consequences of different growth rates in broiler breeder and layer hens on embryogenesis, metabolism and metabolic rate: A review. Poultry Science 2015;94(4):728-733.

Cavero D, Schmutz M. Relationship between egg quality traits and hatchability in pure-line white layer strains. Proceedings of the European Poultry Symposium on Quality of Poultry Meat, and Quality of Eggs and Egg Production; 2009 Jun 21-25; Turku. Finland: World Poultry Science Association; 2009. p.7.

Cordeiro CN, Bastos-Leite SC, Vasconcelos FC, Goulart CC, Sousa AM, Costa AC. Chelated minerals and limestone particle sizes on performance and bone quality of brown-egg layers. Brazilian Journal of Poultry Science 2017;19:35-42. Special number

Duncan DB. Multiple range and multiple F test. Biometrics 1955;11:1-42.

Johnson AL. Ovarian follicle selection and granulosa cell differentiation 1 Poultry Science 2015;94(4):781-785.

Kim MH, Seo DS, Ko Y. Relationship between egg productivity and insulinlike growth factor-I genotypes in Korean native Ogol chickens. Poultry Science 2004;83(7):1203-1208.

Oruwari BM, Brody T. Roles of age, body weight, and composition in the initiation of sexual maturation of Japanese quail (Coturnix coturnix japonica). British Poultry Science 1988;29 (3):481-488.

Renema RA, Robinson FE, Oosterhoff HH, Feddes JJR, Wilson JL. Effects of photostimulatory light intensity on ovarian morphology and carcass traits at sexual maturity in modern and antique egg-type pullets. Poultry Science 2001;80(1):47-56. 
Renema RA, Robinson FE. Effects of light intensity from photostimulation in four strains of commercial egg layers:1. ovarian morphology and carcass parameters. Poultry Science 2001;80(8):1112-1120.

Robinson FE, Renema RA, Oosterhoff HH, Zuidhof MJ, Wilson JL. Carcass traits, ovarian morphology and egg laying characteristics in early versus late maturing strains of commercial egg-type hens. Poultry Science 2001;80(1):37-46.

SAS Institute Inc. SAS/STAT user's guide (Release 8). Version 9.3. Cary; 2004.

Savegnago RP, Caetano SL, Ramos SB, Nascimento GB, Schmidt GS, Ledur $\mathrm{MC}$ et al. Estimates of genetic parameters, and cluster and principal components analyses of breeding values related to egg production traits in a White Leghorn population. Poultry Science 2011:90(10):21742188

Shivaprasad HL, Jaap RG. Egg and yolk production as influenced by liver weight, liver lipid and plasma lipid in three strains of small bodied chickens. Poultry Science 1977;56 (5):1384-1390.

Stifani S, Barber D, Nimpf J, Schneider W. A single chicken oocyte plasma membrane protein mediates uptake of very low density lipoprotein and vitellogenin. Proceedings of National Academy of Science of the United States of America 1990;87(5):1955-1959. 